\title{
POLÍTICAS E PROCESSOS FORMATIVOS DE PROFESSORES EDUCAÇÃO INFANTIL
}

\section{POLICIES AND FORMATION PROCESSES OF TEACHERS IN EARLY CHILDHOOD EDUCATION}

\author{
Filomena Maria de Arruda Monteiro ${ }^{25}$ \\ Rute Cristina Domingos da Palma ${ }^{26}$ \\ Sandra Pavoeiro Tavares Carvalho ${ }^{27}$
}

\section{RESUMO}

O texto objetiva apresentar o percurso vivenciado na implementação do curso de Especialização em Docência na Educação Infantil desenvolvido pela Universidade Federal de Mato Grosso (UFMT), em parceria com o Ministério da Educação (MEC), curso esse inserido nas ações da Política Nacional de Formação de Professores para a Educação Infantil, no período de 2010 a 2016. A oferta de 10 turmas de Especialização e 8 turmas de Aperfeiçoamento oportunizou a formação continuada de aproximadamente 800 profissionais da Educação Infantil pertencentes a 23 municípios do estado de Mato Grosso. O processo formativo segundo os cursistas favoreceu não só a compreensão sobre a infância e a educação infantil, a articulação entre teoria e prática, como também significativa melhora na relação professor-aluno, oferecendo novos conhecimentos e diferentes possibilidades na elaboração do planejamento e execução de atividades. Além disso, constatou-se que a experiência foi enriquecedora para a maioria dos participantes uma vez que após o término do curso alguns foram convidados para fazer parte da equipe da Secretaria de Educação de seus municípios, outros aprovados em processo seletivo para cargos de gestão, de coordenação pedagógica e ainda para o Mestrado sinalizando a importância da formação continuada e o engajamento pessoal nesse processo. Enfim, considera-se que a reflexão crítica sobre as políticas, as teorias e as práticas, pode oportunizar a vivência de novas propostas pedagógicas na perspectiva da reflexão-ação-reflexão, abrindo novos caminhos na perspectiva do desenvolvimento profissional docente.

Palavras-chave: Educação Infantil; Política de Formação; Especialização; Aperfeiçoamento.

\footnotetext{
ABSTRACT

This paper aims at presenting the route experienced during the implementation of the Specialization Course in Teaching in Early Childhood Education, developed by the Federal University of Mato Grosso (UFMT) in partnership with the Ministry of Education (MEC). The course is part of the National Policy on Teaching Formation for Early Childhood

${ }^{25}$ Docente do Departamento de Ensino e Organização Escolar e do Programa de Pós-graduação em Educação do Instituto de Educação da Universidade Federal de Mato Grosso.

${ }^{26}$ Docente do Departamento de Ensino e Organização Escolar e do Programa de Pós-graduação em Educação do Instituto de Educação da Universidade Federal de Mato Grosso.

${ }^{27}$ Docente do Departamento de Psicologia do Instituto de Educação da Universidade Federal de Mato Grosso.

Revista REAMEC, Cuiabá - MT, n.05, Volume 1, dezembro 2016, ISSN: 2318 - 6674

Revista do Programa de Doutorado da Rede Amazônica de Educação em Ciências e Matemática

http://revistareamec.wix.com/revistareamec
} 


\section{REVISTA REAMEC}
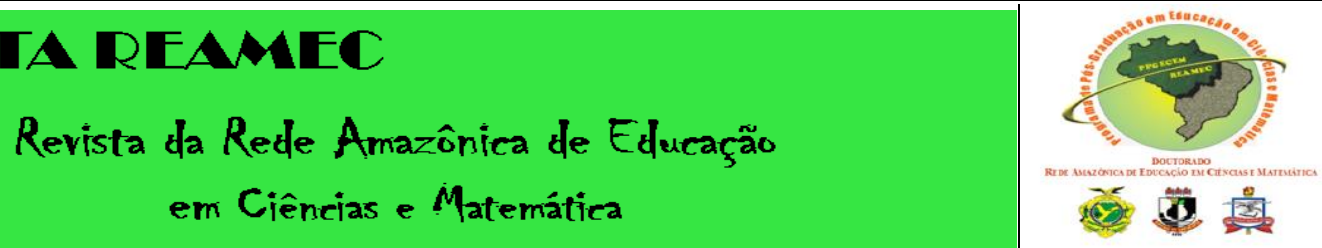

Education from 2010 to 2016. The offer of 10 Specialization classes and 8 Improvement classes provided the opportunity continued training of approximately 800 professionals from Childhood Education, who belong to 23 municipalities in Mato Grosso state. According to the course participants, the training process contributed not only to the understanding of childhood and early childhood education and the relationship between theory and practice, but also to the significant improvement in the teacher-student relationship, which provided them with new knowledge, as well as different possibilities in preparing the planning and execution of activities. Furthermore, the experience was found to be enriching for most participants since after the course some of them were invited to be part of the Secretariat team of Education in their municipalities; others were approved in the selection process for management and pedagogical coordination positions, or for Masters degrees. They were indicators of the importance of continuing education and personal involvement in the process. Finally, it is considered that the critical reflection on the policies, theories, and practices can create opportunities to experience new pedagogical proposals from the perspective of reflection-action-reflection, breaking new ground in the teacher professional development perspective.

Keywords: Childhood Education; Formation Policy; Specialization; Improvement.

\section{INTRODUÇÃO}

Pretendemos com este texto, apresentar o percurso vivenciado na implementação do curso de Especialização em Docência na Educação Infantil desenvolvido pela Universidade Federal de Mato Grosso (UFMT), em parceria com o Ministério da Educação (MEC), curso esse inserido nas ações da Política Nacional de Formação de Professores para a Educação Infantil. Compreender a docência em seus diversos sentidos de formação significa buscar diferentes referenciais que possam contribuir para um olhar plural, o que implica considerar que as políticas educacionais tenham ocupado um espaço significativo sobre os elementos essenciais desse processo ao tentar contribuir na (re)definição do lugar de atuação e constituição da identidade profissional. Nesse sentido optamos por enfrentar o desafio de ao implementar tal programa, refletir sobre o projeto que desenvolvemos, considerando ao longo desses anos (2010 a 2016) nossa concepção de formação e currículo, em que procuramos aproximação com as experiências acumuladas nas unidades de ensino e nos demais espaços socioculturais.

A Lei de Diretrizes e Bases da Educação Nacional - 9394/96 ao assegurar o direito à educação de crianças de 0 a 5 anos, instituiu a Educação Infantil como etapa inicial da Educação Básica exigindo formação em nível superior para os professores que atuam nessa área. A partir de então, políticas públicas e programas de formação docente voltadas ao atendimento educacional no âmbito da creche e da pré-escola, passaram a ser alvo de atenção 


\section{REVISTA REAMEC}

\section{Revista da Rede Amazônica de Educação \\ em Ciências e Matemática}

e nesse processo, a universidade apresentou-se como uma instituição que desempenha papel fundamental, pois "cabe a ela não só formar os professores para ingressarem no magistério, mas também oferecer acompanhamento as suas ações e dar continuidade à formação em serviço" (ALMEIDA, 2005, 14).

Entendendo que a formação continuada precisa estar atrelada às mudanças sociais, econômicas, políticas e educacionais desencadeadas nas últimas décadas e deve estimular tanto o desenvolvimento pessoal, profissional e institucional dos professores quanto o trabalho colaborativo que visa transformar a prática, Imbernón (2010) afirma que ela

deveria apoiar, criar e potencializar uma reflexão real dos sujeitos sobre sua prática docente nas instituições educacionais e em outras instituições, de modo que lhes permitisse examinar suas teorias implícitas, seus esquemas de funcionamento, suas atitudes, etc., estabelecendo de forma firme um processo constante de auto avaliação do que se faz e por que se faz. (IMBERNÓN, 2010, p.47)

Nessa perspectiva, segundo o referido autor a capacidade profissional dos professores não termina na formação técnica, disciplinar e conceitual, mas deve alcançar o terreno prático e as concepções pelas quais ele estabelece a sua ação pedagógica.

Em 2009,o MEC amparado em estudos e documentos reuniu num esforço nacional, regional e local a definição de uma política nacional de formação de profissionais da Educação Básica incluindo entre suas ações o projeto de um curso de Especialização em Educação Infantil, junto a Coordenação Geral de Formação de Professores(CGFORM) em parceria com a Coordenação Geral de Educação Infantil (COEDI) e a participação de Universidades.

O curso de Especialização que teve como objetivo atender as demandas de formação de profissionais da Educação Infantil explicitadas nos Planos de Ações Articuladas (PAR), foi colocado em desenvolvimento a partir de 2010, inicialmente por 13 universidades federais, dentre elas a UFMT, e especificamente no nosso caso, reforçou e deu continuidade as ações formativas que já vinham sendo desenvolvidas pela instituição.

Assim, o referido curso oferecido na modalidade presencial, buscou propiciar aos professores da área oportunidades de ampliar e aprofundar a análise das especificidades das crianças de 0 a 5 anos, relacionando-as às políticas públicas federais, estaduais, municipais e as práticas pedagógicas para a educação em creches e pré-escolas, considerando a realidade e 


\section{REVISTA REAMEC}

\section{Revista da Rede Amazônica de Educação \\ em Ciências e Matemática}

as experiências locais, as características do corpo docente, da infraestrutura das unidades escolares e a equipe técnica existente. Em 2012, após avaliação das ações desenvolvidas, o MEC constata que o curso proposto apresentava ênfase em aspectos históricos da Educação Infantil, em especificidades do desenvolvimento da criança e se voltava para a pesquisa, propondo que o mesmo fosse revisto e centralizasse foco na docência, como forma de explicitar a sua intenção e o público alvo prioritário. Dessa maneira, de 2012 a 2016 o curso após reestruturação, passou a ser intitulado Especialização em Docência na Educação Infantil e organizado em torno dos eixos que se seguem:

Eixo I - Fundamentos da Educação Infantil: aborda as concepções de infância e a Educação Infantil nas políticas nacionais e municipais, com o objetivo de compreender as relações existentes entre elas, focalizando as infâncias e as crianças dos diferentes grupos humanos como seres que se constituem em suas interações com os outros, com a natureza e com a diversidade de práticas culturais. Enfoca a emergência da educação da criança pequena em espaços coletivos, as políticas públicas de Educação Infantil tendo como referências os documentos legais orientadores da área em questão.

Eixo II - Identidades, prática docente e pesquisa:se caracteriza como eixo transversal, e integra os conteúdos das disciplinas e as atividades realizadas ao longo do curso aos problemas, ações e projetos vivenciados pelos cursistas nas instituições educativas. Constitui-se como espaço para o desenvolvimento de atitude investigativa e reflexões sobre as experiências e práticas profissionais com crianças pequenas, em creches e pré-escolas, com as famílias e a população local. Nele são articulados temas como memória, pesquisa e intervenção na Educação Infantil, focalizando as identidades pessoais, profissionais, institucionais e as possibilidades para ressignificação da ação docente.

Eixo III - Cotidiano e ação pedagógica: busca junto aos cursistas, promover uma ação pedagógica sustentada na observação, na escuta dos bebês e das crianças pequenas como referência para a prática educativa e a implementação de uma prática educativa inclusiva. Tem como eixos norteadores as interações, a brincadeira, as expressões infantis, a promoção da autonomia e da autoria das crianças de diferentes idades. Visa promover a reflexão sobre a prática pedagógica dos cursistas, por meio do enfoque das brincadeiras, das interações, da linguagem, das artes (dança, música, desenho, artes visuais, teatro, literatura) da cultura e dos recursos midiáticos e tecnológicos, discutindo formas de planejamento, registros, 


\section{REVISTA REAMEC}

Revista da Rede Amazônica de Educação

em Ciências e Matemática

documentação e avaliação na Educação Infantil, bem como a relação família/escola, e a organização do espaço, do tempo e rotinas.

A oferta do curso de Especialização se deu em regiões que apresentaram demandas para formação de professores em Educação Infantil indicadas via Plataforma Freire, via Página | 98 UNDIME, PDE Interativo e Fórum Estadual de Formação Docente. Assim, o curso foi realizado em cidades denominadas Polo, cidades essas que possuíam campus da UFMT e agregaram os municípios do entorno, como descrito na Tabela 1.

Tabela 1- Distribuição de Municípios por Polo

\begin{tabular}{|c|c|}
\hline Polos & Municípios atendidos \\
\hline Baixada Cuiabana & $\begin{array}{c}\text { Cuiabá } \\
\text { Chapada dos Guimarães } \\
\text { Santo Antônio do Leverger } \\
\text { Barão de Melgaço }\end{array}$ \\
\hline Barra do Garças & $\begin{array}{c}\text { Alto da Boa Vista } \\
\text { Aragarças } \\
\text { Araguaiana } \\
\text { Barra do Garças } \\
\text { Pontal do Araguaia } \\
\text { Torixoréu } \\
\end{array}$ \\
\hline Rondonópolis & $\begin{array}{c}\text { Pedra Preta } \\
\text { Primavera do Leste } \\
\text { Rondonópolis } \\
\end{array}$ \\
\hline Sinop & $\begin{array}{c}\text { Alta Floresta } \\
\text { Itaúba } \\
\text { Ipiranga do Norte } \\
\text { Nova Santa Helena } \\
\text { Marcelândia } \\
\text { União do Sul }\end{array}$ \\
\hline
\end{tabular}

Revista REAMEC, Cuiabá - MT, n.05, Volume 1, dezembro 2016, ISSN: 2318 - 6674 


\section{REVISTA REAMEC}

Revista da Rede Amazônica de Educação

em Ciências e Matemática

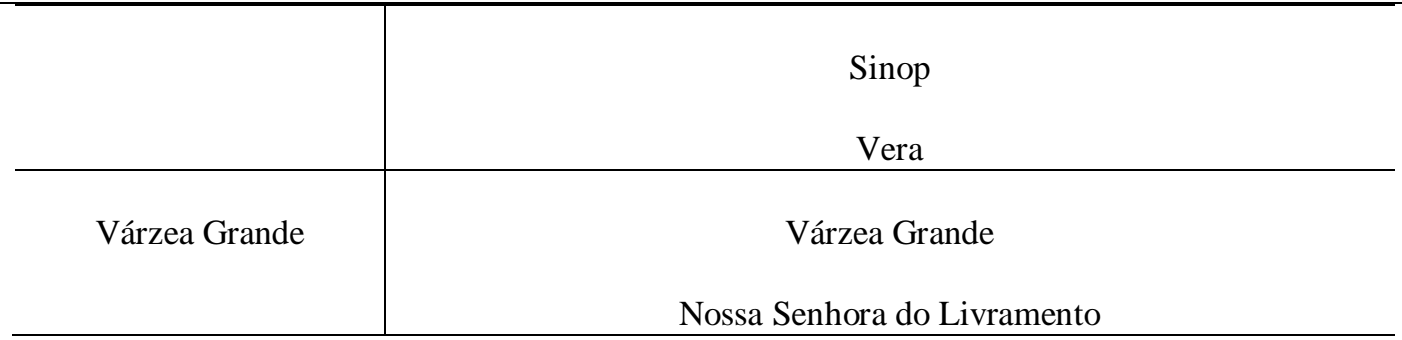

Fonte: arquivo dos autores

Em sua primeira edição, entre os anos de 2010/2012 o curso foi ofertado nos Polos de Sinop, de Barra do Garças e Baixada Cuiabana. No período de 2012 a 2014 contemplamos os professores dos Polos Baixada Cuiabana e Várzea Grande tendo em vista a grande demanda pelo curso nesses polos e entre 2014/2016 atendemos professores dos Polos Baixada Cuiabana e Rondonópolis. Com essa configuração foram beneficiados professores de 23 municípios do estado de Mato Grosso, que pleitearam a vaga e ao apresentarem documentação compatível com os critérios estabelecidos pelo MEC, tiveram a oportunidade de participar dessa ação formativa.

Direcionado a professores da rede pública, tínhamos como critério para participação no curso de Especialização os seguintes itens: ser graduado em Pedagogia, possuir 03 anos de experiência na Educação Infantil, ser efetivo na rede pública, permanecer em efetivo exercício na Educação Infantil durante o processo formativo; permanecer atuando na Educação Infantil, no mínimo, pelo mesmo período de realização do curso após a formação e ter disponibilidade de pelo menos 10horas semanais para estudos complementares. Assim, considerando as exigências e o cumprimento das normas estabelecidas pelo curso quanto à frequência mínima, desempenho acadêmico e elaboração/defesa do trabalho monográfico, a UFMT se responsabilizou pela formação de 477 professores especialistas, sendo esses distribuídos em três etapas de oferta: primeira turma (2010/2012) com 192concluintes, segunda turma (2012/2014) encerrada com 132 especialistas e terceira turma (2014/2016) composta por 153 concluintes.

Interessadas em conhecer quem eram os nossos cursistas, elaboramos a caracterização do grupo de professores participantes, buscando para tais informações constantes na ficha de matrícula dos mesmos. Conforme dados levantados encontramos que a maioria dos professores possui formação inicial em Pedagogia, curso indicado como necessário para o trabalho na Educação Infantil e nos anos iniciais do Ensino Fundamental, 


\section{REVISTA REAMEC}

\section{Revista da Rede Amazônica de Educação \\ em Ciências e Matemática}

como propõe a Lei de Diretrizes e Bases da Educação Nacional - LDBEN 9394/96.

Verificamos também que os participantes em geral eram provenientes de cursos de Pedagogia oferecidos através da modalidade de formação em serviço - presencial ou a distância, que se deu em parceria firmada entre MEC/UFMT/Secretarias Municipais de Educação, para atender as exigências da legislação vigente e as demandas do Estado de Mato Grosso.

Assim como várias pesquisas têm apontado, verificamos que $98 \%$ dos participantes do curso de Especialização em Docência na Educação Infantil é do gênero feminino indicando que a presença de professores do gênero masculino vinculados as unidades escolares que atendem a Educação Infantil é ainda mínima. Os dados da Tabela 2 ilustram essa colocação.

Tabela 2- Distribuição dos professores cursistas por turma e gênero

\begin{tabular}{|c|c|c|c|c|c|c|}
\hline Característi & & \multicolumn{5}{|c|}{ Turmas } \\
\hline \multirow{3}{*}{ Gênero } & \multicolumn{2}{|c|}{$2010 / 2012$} & \multicolumn{2}{|c|}{$2012 / 2014$} & \multicolumn{2}{|c|}{$2014 / 2016$} \\
\hline & Fem. & Masc. & Fem. & Masc. & Fem. & Masc. \\
\hline & 189 & 03 & 130 & 02 & 150 & 03 \\
\hline
\end{tabular}

Fonte: arquivo dos autores

Essa predominância do gênero feminino na Educação Infantil conforme Rosemberg e Amado (1992) pode ser explicada por questões históricas e culturais uma vez que tanto na esfera doméstica como na esfera pública a responsabilidade pela educação e cuidado das crianças é das mulheres, a atribuição da educação se deve ao universo feminino e à docência junto a crianças ainda carrega as marcas culturais da maternagem.

A faixa etária, assim como a raça/cor dos professores cursistas foi também um aspecto considerado na análise, sendo os dados apresentados na Tabela 3.

Tabela 3 - Distribuição dos professores cursistas por faixa etária, raça/cor

\begin{tabular}{l|c|c|c}
\hline Características & \multicolumn{3}{|c}{ Turmas } \\
\hline Faixa etária & $2010 / 2012$ & $2012 / 2014$ & $2014 / 2016$ \\
\hline 20 a 29 anos & 09 & 06 & 16 \\
\hline
\end{tabular}




Revista da Rede Amazônica de Educação
em Ciências e Matemática

\begin{tabular}{l|c|c|c}
\hline Raça/cor & $2010 / 2012$ & $2012 / 2014$ & $2014 / 2016$ \\
\hline Branca & 57 & 25 & 32 \\
\hline Amarela & 0 & 03 & 03 \\
\hline Preta & 15 & 36 & 30 \\
\hline Parda & 20 & 68 & 88 \\
\hline Indígena & 0 & 0 & 0 \\
\hline
\end{tabular}

Fonte: arquivo dos autores

No que diz respeito a faixa etária, constatamos que $42 \%$ dos professores cursistas se situam entre 30 e 39 anos de idade e uma parcela de $38 \%$ entre 40 e 49 anos. Ao somarmos esses percentuais observamos que $80 \%$ dos professores que frequentaram o curso de especialização possuem idades entre 30 e 49 anos, portanto são adultos que provavelmente já se encontram em fase de estabilização profissional. Constatamos ainda a existência de uma pequena parcela de professores situados na faixa dos 20 aos 29 anos, portanto considerados adultos jovens e iniciantes na carreira docente e apenas $10 \%$ com idade acima de 50 anos o que nos permite inferir que são professores que se encontram próximos a aposentadoria.

Diante do quesito raça/cor, os dados apontaram que $37 \%$ dos cursistas se consideram como pardos, $24 \%$ se caracterizam como brancos e $17 \%$ se autodenominam pretos. Ressaltase que nenhum cursista se identificou como indígena e que apenas $0,6 \%$ indicou ser da raça amarela. 


\section{REVISTA REAMEC}

\section{Revista da Rede Amazônica de Educação \\ em Ciências e Matemática}

Como forma de conhecer um pouco sobre a atuação profissional dos professores cursistas buscamos informações sobre a localização das unidades escolares e a faixa etária dos alunos com os quais eles trabalham, dados esses que foram organizados na Tabela 4.

Tabela 4 - Distribuição dos professores cursistas por local e área de atuação

\begin{tabular}{l|l|l|l|l|l}
\hline Turma & Zona Urbana & Zona Rural & Creche & Pré-escola & $\begin{array}{l}\text { Secretaria } \\
\text { Municipal }\end{array}$ \\
\hline $2010 / 2012$ & 192 & 0 & 83 & 36 & 03 \\
\hline $2012 / 2014$ & 131 & 01 & 105 & 27 & 02 \\
\hline $2014 / 2016$ & 147 & 06 & 103 & 54 & 01 \\
\hline
\end{tabular}

Verificamos que $98 \%$ dos professores participantes do curso de Especialização são provenientes de unidades escolares localizadas na zona urbana e apenas $2 \%$ de escolas da zona rural, dado esse que merece atenção dos órgãos públicos, uma vez que o direito a educação deve ser garantido a todas as crianças dentre elas as que moram no campo.

No que diz respeito a faixa etária dos alunos atendidos, constatamos entre os cursistas a predominância de professores atuantes em creches (62\%) e que lidam, portanto, com ações educativas direcionadas a crianças de 0 a 3 anos de idade e suas especificidades. Do total de professores $25 \%$ atuam junto a crianças de 04 e 05 anos matriculadas na préescola que na maioria das vezes funciona em Escolas Municipais de Educação Básica (EMEBs), juntamente com os anos iniciais do Ensino Fundamental. O curso acolheu ainda, $13 \%$ de profissionais que integram as equipes de Educação Infantil das Secretarias Municipais de Educação e prestam serviços junto as unidades escolares que atendem a população alvo dessa etapa educativa exercendo a função de assessores pedagógicos.

Outro quesito que nos chamou a atenção foi quanto ao vínculo empregatício que os profissionais da Educação Infantil estabelecem com as Secretarias Municipais de Educação (SME). Embora todos os cursistas pertencentes a Especialização fossem concursados e efetivos no serviço público, bem como licenciados em Pedagogia, critérios esses estabelecidos para se inscrever no curso de Especialização, foi notório o número expressivo de profissionais contratados e atuantes nessa etapa da Educação Básica, que não puderam ser contemplados. 


\section{REVISTA REAMEC}

\section{Revista da Rede Amazônica de Educação \\ em Ciências e Matemática}

Nesse contexto, o questionamento presente nas reuniões de avaliação do projeto junto a equipe do MEC foi: como implementar uma proposta curricular para a Educação Infantil e melhorar a qualidade das ações das unidades negando formação a esses profissionais? Para atender a essa demanda foi proposto, em 2012, que as instituições formadoras, além de ofertarem a Especialização, assumissem também cursos de Aperfeiçoamento.

Nesse contexto, três cursos de Aperfeiçoamento foram propostos para que as universidades fizessem a opção de ofertá-los de acordo com as necessidades locais e potencialidades das equipes formadoras, quais sejam: Educação Infantil, Infâncias e Arte;

Currículo, Planejamento e Organização do Trabalho Pedagógico na Educação Infantil e Campos de Experiências e Saberes e Ação Pedagógica na Educação Infantil.

A primeira oferta do curso de Aperfeiçoamento na UFMT se deu em 2013, no polo de Barra do Garças tendo como foco Currículo, Planejamento e Organização do Trabalho Pedagógico na Educação Infantil, que organizado em dois módulos, totalizou 150 horas. Em seu módulo inicial apresentou uma problematização sobre as Infâncias e crianças na cultura contemporânea, a concepção de educação infantil nas políticas nacionais e municipais de educação, a identidade e formação do professor de Educação Infantil. Além disso, desencadeou discussões sobre as relações étnico-raciais e de gênero na infância, diversidades e a inclusão. No segundo módulo as questões pertinentes foram acerca do currículo, planejamento e ação pedagógica. Nesse modulo, problematizou-se a implementação das Diretrizes Curriculares Nacionais da Educação Infantil, a elaboração de proposta pedagógica para os diferentes ciclos etários da Educação Infantil, as especificidades das práticas com bebês, o planejamento, organização e gestão do espaço, do tempo e das rotinas em creches e pré-escolas, bem como a avaliação na Educação Infantil e a relação entre escola, família e comunidade. Do curso ofertado no município de Barra do Garças participaram 50 professores que exerciam suas funções nas creches e escolas que atendiam a Educação Infantil e que possuíam vínculo empregatício com a Secretaria Municipal de Educação por meio de contrato temporário.

Para o polo Baixada Cuiabana foi proposta o curso de Aperfeiçoamento com ênfase nos Campos de Experiências e Saberes e Ação Pedagógica na Educação Infantil, também com carga horária de 150 horas e dividido em dois módulos. O primeiro módulo assim como 


\section{REVISTA REAMEC}

\section{Revista da Rede Amazônica de Educação \\ em Ciências e Matemática}

o curso ofertado em Barra do Garças, tratou das Concepções de infância, desenvolvimento e educação infantil, no entanto o segundo módulo denominado Campos de experiências e saberes na Educação Infantil teve como objetivo discutir a implementação das Diretrizes Curriculares Nacionais da Educação Infantil e temas relacionados a cultura, ludicidade, múltiplas linguagens, jogos e brincadeiras, cultura oral e escrita, natureza e cultura, conhecimento lógico matemático, corpo e movimento. Desencadeou ainda, estudos sobre a inclusão, diversidade, saúde, higiene, alimentação e bem-estar nas instituições de Educação Infantil e das especificidades das práticas com bebês. Dessa forma, possibilitou que os profissionais envolvidos ampliassem os conhecimentos a partir da análise e reflexão sobre as políticas públicas e as práticas pedagógicas na Educação Infantil.

Entre os anos de 2014 e 2016 o polo Baixada Cuiabana, continuou a oferta do curso de Aperfeiçoamento Campos de Experiências e Saberes e Ação Pedagógica na Educação

Infantil, ampliando a oportunidade para que vários profissionais da Educação Infantil pudessem participar dessa essa ação formativa, como apresentado na Tabela 5.

Tabela 5 - Turmas e número de professores participantes

\begin{tabular}{l|l|l|l}
\hline Polo Baixada Cuiabana & 2014 & 2015 & 2016 \\
\hline Turma 1 & 40 & 40 & 65 \\
\hline Turma 2 & 40 & 40 & 65 \\
\hline Turma 3 & 40 & - & - \\
\hline Total & 120 & 80 & 130 \\
\hline
\end{tabular}

Fonte: arquivo dos autores

Os dados indicam que o curso de aperfeiçoamento contemplou 200 profissionais nos anos de 2014 e 2015 e que 130 estão sendo atendidos em 2016, por meio de duas turmas que se encontram em andamento. Assim, tem sido beneficiado professores e técnicos de desenvolvimento infantil (TDIs) que em sua maioria são contratados, gestores das unidades escolares e profissionais da equipe técnica da Educação Infantil das Secretarias de Educação, que atuam nos municípios de Cuiabá, Várzea Grande e Chapada dos Guimarães e municípios circunvizinhos. 


\section{REVISTA REAMEC}

Revista da Rede Amazônica de Educação

em Ciências e Matemática

\section{ALGUMAS CONSIDERAÇÕES}

Os cursos ofertados pela UFMT em parceria com o MEC, ao atenderem as demandas da Educação Infantil no estado de Mato Grosso foram considerados pelos professores participantes, uma ação formativa de grande importância, pois possibilitou a relação constante entre teoria/prática e a interlocução permanente entre pesquisa extensão e ensino, que se deu Página I 105 por meio das leituras e releituras acerca do cotidiano e de intervenção na ação pedagógica no contexto do trabalho do profissional de Educação Infantil.

Pautado na reflexão crítica sobre as políticas, as teorias e as práticas, pode oportunizar a vivência de novas propostas pedagógicas na perspectiva da reflexão-açãoreflexão, abrindo novos caminhos na perspectiva do desenvolvimento profissional docente. A experiência vivida foi enriquecedora para a maioria dos participantes. Cursistas após o termino do curso alguns foram convidados para fazer parte da equipe da Secretaria de Educação de seus municípios, outros aprovados em processo seletivo para cargos de gestão, de coordenação pedagógica e ainda para o Mestrado sinalizando a importância da formação continuada e o engajamento pessoal nesse processo.

Como fruto do trabalho coletivo a equipe de coordenação dos cursos organizou a obra intitulada Processos e práticas na formação de professores da Educação Infantil, que em seus dois volumes apresenta pesquisas realizadas por docentes que ministraram disciplinas, por docentes colaboradores e por cursistas após realização de suas monografias.

Os participantes contaram que o curso ao oportunizar novos conhecimentos favoreceu significativa melhora na relação professor-aluno e auxiliou no planejamento das aulas oferecendo diferentes possibilidades de trabalhar as áreas de conhecimento. (NIENOW; SPINELLI, 2012). Assim, as concepções de Educação Infantil, ao final do curso, apresentaram uma característica para além das definições de "receituários" e exibiram um teor reflexivo, pautado em um conjunto de experiências propiciadas durante o processo de formação continuada na e em seu contexto de atuação docente, como apontam os participantes:

Antes do curso de especialização eu tinha esse olhar da criança que só precisa de cuidado, hoje eu já tenho o olhar da criança que está em desenvolvimento, precisa aprender e que ela aprende na relação comigo com outras crianças, com outros professores, com outros adultos, com a família e tudo que elas trazem tem que ser respeitado, tem que ser assim levado para 
sala de aula, eu acho que muda até a afetividade. (Prof. Baixada Cuiabá), (MARTINEZ, 2014). Eu comecei a ver o desenvolvimento mesmo da criança, o comportamento dela, eu não prestava muito atenção, não sei se era distração ou se, eu acho que foi o curso que me deu uma acordada, eu acordei para prestar atenção na criança de verdade, no que ela sente, até quando ela fala, ela fica assim: humhumhumm! Mostrando com o dedinho eu já fico: nossa! Ela não fazia isso e ela está mostrando que ela quer a água, balbuciando alguma coisa, pedindo alguma coisa. Então a gente começa a 106 prestar atenção em pequenos detalhes, pequenos mesmos. (Prof. Cuiabá, 27) (MARTINEZ, 2014)

Com esse retrato parcial, porém não menos complexo de nossa realidade em curso quanto ao atendimento aos professores que atuam na Educação Infantil no estado de Mato Grosso, retomamos nosso desafio anteriormente mencionado, apontando que por ora temos tentado compreender em profundidade algumas tensões e potencialidades desse processo formativo considerando especificamente as narrativas dos professores, suas subjetividades, identidades culturais e que de certa forma como autores de políticas curriculares e de formação. Esse tem sido o caminho construído por nós.

\section{REFERÊNCIAS}

ALMEIDA, M. I. Formação contínua de professores em face das múltiplas possibilidades e dos inúmeros parceiros existentes hoje. In: BRASIL, Ministério da Educação. Formação contínua de professores. Boletim 13, ago.,2005.

BRASIL, LDB: Lei de Diretrizes e Bases da Educação Nacional: Lei no 9394, de 20 de dezembro de 1996, que estabelece as Diretrizes e Bases da Educação Nacional- $5^{\text {a }}$ Ed. Brasília: Câmara dos Deputados, Coordenação Edições Câmara, 2010.

IMBERNÓN, F. Formação Continuada de Professores. Porto Alegre: Artmed, 2010.

\section{MINISTÉRIO DA EDUCAÇÃO. Curso de Especialização e de Aperfeiçoamento em}

Docência na Educação Infantil. Secretaria de Educação Básica. Coordenadoria Geral de Educação Infantil. Universidade Federal de Mato Grosso, 2013.

\section{MARTINEZ, Michelle Cristine Pinto Tyszka. Relatório de Avaliação do Curso de Especialização em Docência na Educação Infantil. Cuiabá-MT, 2014.}

NIENOW, Naiara dos Santos; SPINELLI, Larissa Silva Freire. Relatório de Avaliação do Curso de Especialização em Educação Infantil. Cuiabá-MT, 2012.

ROSEMBERG, F.; AMADO, C. Mulheres na escola. Cadernos de Pesquisa, São Paulo: Cortez. Fundação Carlos Chagas, n. 80, fev. ,1992. 